There is evidence that cereal crops differ in their liability to injury; oats appear to be the most susceptible, barley is intermediate and winter wheat the most resistant. Dr. Allen's experiments on barley have indicated that with a change-over from the sodium salts to the $n$-butyl esters, the greater toxicity to the crop of $2: 4$ dichlorophenoxyacetic acid is accentuated. Mr. J. Fryer (Agricultural Research Council Unit of Experimental Agronomy, Oxford) stressed that any attempt to define the effects on cereals of formulation and volume of application demands an extensive field programme covering several years. A preliminary examination of the results for the 1951 trials on barley suggests that the degree of injury brought about by the application of the triethanolamine salt of $2: 4$-dichlorophenoxyacetic acid at the rate of $0.5 \mathrm{lb}$. of the acid per acre is roughly equivalent to the effects produced by the sodium salt of 2-methyl4-chlorophenoxyacetic acid at $2 \mathrm{lb}$. per acre. Spraying at an early stage prior to the formation of tillers produces the largest number of abnormalities; but even when the proportion of abnormal ears is exceptionally high, this does not necessarily lead to any appreciable loss of yield, although the quality of the grain may be affected.

K. Holly (Agricultural Research Council Unit of Experimental Agronomy, Oxford) pointed out that in commercial practice it is commonly held that a specific amount of these two herbicides is required per acre to destroy a particular weed species and that the volume of solution applied is of little importance. Field investigations at Oxford have revealed a great variability in the effects of changing volume-rate on different species and between different experiments. From experiments in the greenhouse it is already evident that the amount of spray solution retained by the shoot is dependent on the volume of solution applied, and that with the test plants used (mustard and barley) there were marked specific differences in retention as the volume changed. Since a change of droplet size could also affect penetration into the leaf and since the effects of decreasing droplet size on penetration tended to be the reverse of those on retention, it was not surprising that in the field variable results were obtained. Dr. E. K. Woodford (Agricultural Research Council Unit of Experimental Agronomy, Oxford) stated that in his opinion the greater toxicity of the dichloro compound in the field cannot be satisfactorily accounted for in terms of retention and penetration. On the other hand, the evidence, although surprisingly scanty, indicates that at cell-level there is little difference between the two compounds in their inherent toxicity. One is therefore left with the conclusion that the major difference between the compounds is a question of transport or persistence within the plant.

Lastly, Prof. L. J. Audus (Bedford College, London) dealt with some of the factors relating to the breakdown by micro-organisms of $2: 4$ dichlorophenoxyacetic acid, 2-methyl-4-chlorophenoxyacetic acid and $2: 4: 5$-trichlorophenoxyacetic acid in the soil. In perfusion experiments there is first a lag phase when no breakdown occurs followed by a rapid rate of decomposition. The lag phase is shortest for the dichloro compound; complete breakdown of the trichloro compound has not been found even after a pericid of months. Once the phase of rapid decomposition has been reached, there is no subsequent lag perir $\mathbf{d}$ when further additions of the dichloro or methyl compound are made. Since the decomposition can be inhibited by the addition of sodium azide, it is clearly due to micro-organisms; in fact, an organism belonging to the B. globiformis group can be readily isolated. So far attempts to grow this organism in culture media have not been successful, and the further elucidation of the mechanism of breakdown is thereby being hindered.

G. E. BLACKMAN

\section{INSTITUTION OF GAS ENGINEERS AUTUMN RESEARCH MEETING}

THE seventeenth autumn research meeting of the Institution of Gas Engineers was held in London during November 27-28, 1951, under the presidency of Mr. J. H. Dyde.

A statement by Colonel H. C. Smith, then deputy chairman of the Gas Council, which opened the proceedings, outlined the progress which had been made with regard to the future organization of research in the gas industry. The Gas Council considered that its responsibility was primarily fur fundamental research, and took the view that the gas industry's existing research body, the Gas Research Board, was not an appropriate machine for satisfying the duties imposed upon the Council by the Gas Act of 1948. Accordingly, a research advisury committee was appointed which, after reviewing existing investigations, recommended the establishment. of research stations. Two such stations have now been formed, in London and Birmingham, under the direction of Dr. H. Hollings and Dr. F. J. Dent, respectively. In addition, continued Colonel Smith, the connexion between the gas industry and the University of Leeds is to be maintained through a joint committee of the University and the Gas Council. Finally, a small research liaison committee has been formed to ensure effective collaboration and co-ordination of the work.

A feature common to several of the technical papers presented later during the meeting was the successful application of new scientific techniques to the current problems of the gas industry. Thus, C. H. Lewis described a methed of measuring coal travel in continuous vertical retorts which has the advantage over previous methcds of being non-destructive, and hence applicable at any stage in the working life of a retort. A tally of radioactive cobalt is intruduced into the coal charge at the top of the retort, and its position is determined at intervals during its descent by means of water-cooled Geiger counters placed in the combustion chambers.

Again, the high paramagnetic susceptibility of oxygen has been used as the basis of an instrument designed to record the oxygen content of a gas in the range 0-2 per cent by volume. A description of the instrument, which depends for its operation on the generation of a magnetic wind, was given by $R$. $H$. Griffith, who also presented some results obtained by its use for the automatic control of a catalytic plant for the removal of organic sulphur compounds from coal gas.

In the field of gas utilization, a better control of combustion processes, and improved heat transfer from flame gases, should follow from the wider application of experimental techniques adapted by W. A. Simmonds and M. J. G. Wilson for following the path of secondary air towards and into flames. Both the quartz-fibre anemometer and the powder method of flow visualization have been used for determining the flow of air towards small, radially symmetrical diffusion flames of several inflammable 
gases. Experience has proved the powder method to be of more general application, and its use, in conjunction with Schlieren photography for locating flame boundaries, shows that the amount of air entrained by the above type of flame is approximately three times that required for complete combustion. About half the air required for complete combustion flows directly into the reaction zone, the remainder entering that zone by diffusion.

The satisfactory disposal of liquor effluents is a problem which has confronted the gas industry for some time, and one which has assumed greater importance recently as a result of increased gas prcduction, greater sewage flow generally, and new legislation governing the prevention of river pollution. The urgency of the problem was emphasized in two papers dealing with the treatment of gas-works liquor.

C. Cooper and W. E. Bouch outlined a new method of effluent liquor purification in which the residual toxic matter in ammonia stills and other gas-works effluents is destroyed by nitric acid and nitrous acid. Inorganic salts such as ammonium thiosulphate and thiocyanate are converted into comparatively harmless substances, while the decomposition products of the acid are recovered for further use by simple oxidation with air. On the other hand, some nitric acid is lost as a result of its combination with any phenolic bodies present in the effluent.

The second paper, by W. H. Blackburn, T. G. Tomlinson and T. H. Summers, discussed the treatment of gas-works liquor in admixture with sewage in percolating filters. As part of a long-term investigation into the identification and estimation of the constituents of gas liquor, a typical liquor has been divided into a number of fractions and the effect of each fraction on sewage purification determined separately. A new method for the fractionation of the liquor, using methyl isobutyl ketone as solvent, was devised and four main fractions obtained, that containing phenols being further sub-divided by distillation. The greatest deterioration in the quality of a domestic sewage effluent was afterwards shown to be caused by the addition of two fractions, one containing thiocyanate, ammonia and organic sub. stances not extracted from the liquor by the solvent, and the other containing carboxylic acids and 'humic acids'. Further, polyhydric phenols were shown to produce a greater deterioration in effluent quality than monohydric phenols.

Some aspects of the mechanism of the gasification of carbon by carbon dioxide and steam were discussed by J. D. F. Marsh. Laboratory experiments have shown that, when a sample of high-temperature coke is reduced by hydrogen and then treated with carbon dioxide at a temperature below that necessary for gasification, a reaction occurs producing carbon monoxide and a surface layer of adsorbed oxygen which can be removed as water vapour by subsequent treatment with hydrogen. If treated with carbon monoxide instead of hydrogen, most of the oxygen is removed as carbon dioxide; but on the reduced surface, carbon monoxide is then converted to carbon dioxide and carbon. These and other results are then used to elucidate the mechanisms for the reactions between carbon and carbon dioxide or steam.

Finally, the possibilities of recovering pure sulphur from gas-works spent oxide by extraction with toluene were discussed by F. A. Burden and W. B. S. Newling, while R. F. Hayman considered the application of flow visualization techniques to the design of small high-temperature, gas-fired furnaces.

\section{THE MICROSCOPE IN INDUSTRY}

TN Beck's microscope catalogue for 1865 there are engravings of what one supposes to have been typical subjects for the microscopist of that day. One of them is a beautifully drawn but revolting picture of a parasite "to be found in the follicles of the human skin, particularly about the nose. They are easily obtained by ...." Nowadays the microscope serves a more utilitarian purpose, and we may enjoy instead a picture of a speck of oil being coaxed from a soiled textile fibre by a gentle detergent. This particular study was one of many demonstrations set out at a recent exhibition in London to show "How Industry is Using the Microscope". The exhibition, organized by the Royal Microscopical Society, was held at British Medical Association House on November 21 and was opened by the director of the British Scientific Instrument Research Association, Mr. A. J. Philpot.

The microscope, unlike other industrial instruments, was not conceived for industry, and its value there has only in the past few decades been widely recognized. The present extent of its application to industrial problems is shown by the fact that the forty-two contributors to this exhibition came from a wide range of industries : mining and power, agriculture and food, metallurgy, ceramics and glass, paper, rubber, fabrics and leather, paint, pharmacy, photography and industrial biology. Several branches of these industries were appropriately represented by their research associations. If the subjects of the display must be classified, it is safe to say that more than half the exhibits were of applications of the microscope to process control and to the investigation of well-established manufacturing processes. Textiles, leather and cosmetics have been made since the distant time when the advantages of being well clothed, well shod and beautiful were first realized; for the greater part of this time 'process control' has meant no more than feeling, smelling and looking at the fabric or the ointment. Now the man in charge is being offered the support of scientific instruments : the microscope is used to follow the progress of textile fibres, collagen fibres, paper and jute fibres, emulsions, dough, yeasts, metals and minerals through their traditional processes of manufacture. For some of the new products, such as antibiotics, control by microscopical examination is essential. The isolation by micromanipulation of single spores of approved character for the breeding of new lines of yeast and antibiotic-producing fungi (a technique strongly reminiscent of "Brave New World") was well demon-" strated by photomicrograph and working apparatus. The micromanipulators responded to controlling movements with remarkable freedom from backlash.

In analysis, microscopy takes its place with $\mathrm{X}$-ray analysis and the other non-destructive techniques, and it is particularly in this field that the electron microscope finds many applications. Diamond polishing powders, photosensitive grains, pigments, carbon black in rubber, and clay particles in minerals for the ceramic industry are near or beyond the limit of resolution of the light microscope, and examination of raw materials or products containing these particles is now a routine procedure with the electron microscope. As many of the electron micrographs showed, the image is enhanced by shadow-casting. The electron microscope seems to have made a present of 